\title{
Strategi Pengembangan Objek Wisata dan Kontribusinya Terhadap Penerimaan Retribusi di Kabupaten Batang
}

\author{
$\operatorname{Darun}^{1 凶}$, Karsinah $^{2}$ \\ Jurusan Ekonomi Pembangunan,Fakultas Ekonomi, Universitas Negeri Semarang \\ Permalink/DOI: https://doi.org/10.15294/efficient.vii1.27215 \\ Received: July 2017; Accepted: October 2017 ; Published: January 2018
}

\begin{abstract}
This study aims to determine the internal factors, external and development strategy attractions and its contribution to the levy in the District Batang.Metode this research is quantitative descriptive using SWOT analysis. The population in this research manager 5 attractions in Batang in 2016 which amounted to 62 people and sample 67 visitors. The results showed in the Grand Strategy Matrix 5 attractions are in kuadran1. Where the situation can be done by utilizing the strengths and opportunities in order to increase growth Attractions in Batang. Contributions Attractions in Batang against Levies The 2008-2014 The largest contribution is in the year 2012 in the amount of $5.07 \%$ and the lowest is at 2008 which was 1,35.Kesimpulan in this research is the development strategy Attractions in Batang located in quadrant $I$, which uses the strength to take advantage of existing opportunities.
\end{abstract}

Keywords: Development Strategy, Tourist Attractions, Local Levies

\begin{abstract}
Abstrak
Penelitian ini bertujuan untuk mengetahui faktor internal, eksternal dan strategi pengembangan Objek wisata dan kontribusinya terhadap retribusi di Kabupaten Batang.Metode Penelitian ini adalah deskriptif kuantitatif menggunakan analisis SWOT. Populasi dalam penelitian ini pengelola 5 objek wisata di Kabupaten Batang pada tahun 2016 yang berjumlah 62 orang dan sampel 67 pengunjung. Hasil penelitian menunjukkan dalam Matrix Grand Strategy 5 objek wisata berada pada kuadran1. Dimana situasi tersebut dapat dilakukan dengan memanfaatkan kekuatan dan peluang agar dapat meningkatkan pertumbuhan Objek Wisata di Kabupaten Batang. Kontribusi Objek Wisata di Kabupaten Batang terhadap Retribusi Daerah tahun 2008-2014 Kontribusi terbesar ada pada tahun 2012 yaitu sebesar 5,07\% dan terendah ada pada tahun 2008 yaitu sebesar 1,35.Kesimpulan dalam penelitian ini adalah strategi pengembangan Objek Wisata di Kabupaten Batang berada pada kuadran I yaitu menggunakan kekuatan yang dimiliki untuk memanfaatkan peluang yang ada.
\end{abstract}

Kata Kunci: Strategi Pengembangan, Objek Wisata, Retribusi Daerah

How to Cite: Darun, D., \& Karsinah, K. (2018). Strategi Pengembangan Objek Wisata dan Kontribusinya Terhadap Penerimaan Retribusi di Kabupaten Batang. EFFICIENT Indonesian Journal of Development Economics, 1(1), 8-25. https://doi.org/10.15294/efficient.vii1.27215

(c) 2018 Universitas Negeri Semarang. All rights reserved

\footnotetext{
Alamat Korespondensi :

Alamat: Gedung L2 Lantai 2 FE Unnes

Kampus Sekaran, Gunungpati, Semarang, 50229

E-mail : darunlee29@gmail.com
} 


\section{PENDAHULUAN}

Kabupaten Batang merupakan bagian integral dari Provinsi Jawa Tengah yaitu provinsi yang terletak pada jalur perlintasan antara Jawa Barat dengan Jawa Timur, sehingga banyak wisatawan lebih sering melewatkan Jawa Tengah karena hanya sebagai daerah perlintasan. Meskipun demikian, sejatinya Provinsi Jawa Tengah khusunya Kabupaten Batang memiliki potensi pengembangan bisnis wisata yang besar jika para wisatawan tertarik untuk mengeksplorasi daerah wisata di Kabupaten Batang. Terdapat beberapa objek wisata yang berpotensi menambah pendapatan asli daerah di Kabupaten Batang khususnya pendapatan retribusi daerah dari sektor pariwisata antara lain objek wisata Kolam Renang Bandar, Pantai Sigandu, Pantai Ujung Negoro, Taman Hiburan Rakyat (THR) keramat, dan Kebun Teh Pagilaran. Berikut ini merupakan tabel jumlah pengunjung objek wisata kabupaten batang pada tahun 20082014.

Tabel 1. Jumlah pengunjung sarana/wahana wisata di Kabupaten Batang tahun 2008-2014

\begin{tabular}{cccccc}
\multicolumn{6}{c}{ 2008-2014 } \\
\hline \multicolumn{7}{c}{ JUMLAH PENGUNJUNG OBJEK WISATA PERTAHUN } \\
(Ribuan Orang) & & \\
Tahun & THR & Pantai & Pantai & Kebun Teh & Kolam \\
& Keramat & Sigandu & Ujungnegoro & Pagilaran & $\begin{array}{c}\text { Renang } \\
\text { Bandar }\end{array}$ \\
\hline 2008 & 1.891 & 111.023 & 36.729 & 13.271 & 20.542 \\
2009 & 2.827 & 136.242 & 19.143 & 25.100 & 23.395 \\
2010 & 3.242 & 302.986 & 33.801 & 62.997 & 21.236 \\
2011 & 3.406 & 286.310 & 37.246 & 71.700 & 17.729 \\
2012 & 2.572 & 266.968 & 42.788 & 79.600 & 14.563 \\
2013 & 3.452 & 222.804 & 36.693 & 84.600 & 9.318 \\
2014 & 2.527 & 177.186 & 41.327 & 146.682 & 3.900 \\
\hline
\end{tabular}

Sumber: Dinas Kebudayaan dan Pariwisata Kabupaten Batang 2016

Berdasarkan tabel 1 dapat diketahui bahwa perkembangan jumlah pengunjung ke berbagai objek wisata yang ada di Kabupaten Batang sangat statis, namun sebagian besar cenderung mengalami penurunan jumlah pengunjung. Selama 6 tahun terakhir sejak tahun 2009, penurunan jumlah pengunjung jelas terlihat pada objek wisata Kolam Renang Bandar yaitu terjadi pada jangka waktu tahun 2009-2014 dari 23.395 pengunjung menjadi 3.900 pengunjung. Penurunan jumlah pengunjung juga terjadi di Pantai Sigandu yang awalnya mengalami peningkatan jumlah pengunjung paling banyak akan tetapi dalam jangka waktu dari tahun 20112014 mengalami penurunan jumlah pengunjung yaitu sebesar 302.986 menjadi 177.186 orang. Sedangkan objek wisata THR Keramat mengalami penurunan pengunjung pada tahun 2012 sebesar 2.572 orang kemudian mengalami peningkatan kembali di tahun 2013. Objek wisata Pantai Ujung Negoro mengalami penurunan pada tahun 2013 dan kembali mengalami peningkatan pada tahun selanjutnya. Objek wisata yang mengalami kenaikkan jumlah 
pengunjung dari tahun ke tahun hanya terjadi pada objek wisata Kebun Teh Pagilaran yaitu sebesar 13.271 menjadi 146.682 orang dari tahun 2008-2014.

Penurunan jumlah pengunjung tentunya akan berimbas pada penurunan jumlah Pendapatan Asli Daerah (PAD) melalui retribusi objek wisata. Berkembangnya sektor pariwisata di Kabupaten Batang, maka secara tidak langsung akan berdampak pada pembangunan sarana dan prasarana di Kabupaten Batang, dengan demikian diperperlukan sebuah strategi pengembangan pariwisata guna meningkatkan penerimaan atau pendapatan daerah melalui sektor pariwisata. Berikut adalah pendapatan dari objek wisata di Kabupaten Batang:

Tabel 2. Jumlah Pendapatan Retribusi Objek Wisata,Retribusi Daerah dan Pendapatan Asli Daerah (PAD) Kabupaten Batang Tahun 2006-2015

\section{PENDAPATAN PERTAHUN}

(Ribuan Rupiah)

\begin{tabular}{|c|c|c|c|}
\hline Tahun & $\begin{array}{l}\text { Pendapatan Objek } \\
\text { Wisata }\end{array}$ & Retribusi Daerah & Pendapatan Asli Daerah \\
\hline 2008 & 282.569 .400 & 20.811 .791 .556 & 41.192 .714 .868 \\
\hline 2009 & 377.686 .500 & 22.764 .685 .984 & $44.643 .602 .159,48$ \\
\hline 2010 & 666.966 .700 & 24.687 .956 .366 & 45.421 .689 .588 \\
\hline 2011 & 628.051 .400 & $29.644 \cdot 279 \cdot 421$ & 60.155 .029 .031 \\
\hline 2012 & 827.735 .200 & 16.303 .639 .041 & 84.720 .049 .515 \\
\hline 2013 & 786.238 .500 & 35.812 .498 .970 & $112.339 \cdot 381.119$ \\
\hline 2014 & 769.495 .500 & 25.247 .348 .616 & $172.638 .212 .951,92$ \\
\hline
\end{tabular}

Sumber : DPPKAD Kabupaten Batang 2016

Sepanjang tahun 2008 hingga 2010 terjadi kenaikan pendapatan dari sektor pariwisata. Penurunan pendapatan sempat terjadi pada tahun 2011 dan 2013, sampai akhirnya kembali alami kenaikan pada tahun 2014. Dengan demikian, naik turunnya jumlah wisatawan yang berkunjung ke objek wisata di Kabupaten Batang menunjukkan bahwa pengelolaan objek masih perlu mendapatkan perhatian serius dari pemerintah daerah, mengingat bahwa terdapat potensi sumber daya alam yang besar di Kabupaten Batang.

\section{METODE PENELITIAN}

Metode penelitian merupakan cara atau jalan yang ditempuh untuk melaksanakan penelitian, oleh karena itu penggunaan metode yang tepat sangat penting dalam penelitian. Metode dalam penelitian ini menggunakan metode Penelitian Deskriptif Kuantitatif. Penelitian ini sesuai dengan penelitian yang dilakukan oleh Angga Pradikta mengenai metode yang digunakan dalam penelitiannya yaitu menggunakan metode analisis deskriptif kuantitatif. Metode pengumpulan data dalam penelitian ini mengunakan data primer dimana data primer dikumpulkan dari pengelola objek wisata, pengunjung dan Dinas Budaya dan Pariwisata pada tahun 2016 dengan menggunakan daftar pertanyaan, observasi langsung atau wawancara langsung dan dokumentasi. Metode analisis merupakan suatu usaha untuk menentukan jawaban atas pertanyaan tentang rumusan dan hal-hal yang 
diperoleh dalam suatu penelitian. Data yang sudah masuk dan sudah terkumpul dianalisis untuk menjawab tujuan dari penelitian.

\section{HASIL DAN PEMBAHASAN}

\section{Analisis SWOT}

Analisis SWOT merupakan identifikasi sistematis faktor dan strategi yang merefleksi keduanya.Untuk itu diperlukan analisis SWOT yang terdiri dari Strenght (Kekuatan), Weakness (Kelemahan), Oppurtunity (Peluang) dan Threat (Ancaman).

\section{Identifikasi Faktor-faktor Strategi Internal dan Eksternal}

Faktor-faktor strategi Internal pengembangan objek wisata di Kabupaten Batang untuk faktor kekuatan yaitu keramahan pengelola objek wisata, letak objek wisata yang strategis, kondisi keamanan yang baik, suasana objek yang memberi kenyamanan, adanya sarana transportasi yang mendukung dan harga tiket yang masih terjangkau. Sedangkan untuk kelemahan yaitu promosi objek wisata yang kurang, program pengembangan masih sederhana, keterbatasan anggaran untuk objek wisata, kebersihan objek wisata yang kurang, kurangnya tenaga kerja dan minimnya sarana dan prasarana objek wisata. Faktor-faktor strategi Eksternal pengembangan objek wisata di Kabupaten Batang untuk faktor Peluang yaitu adanya otonomi daerah, aksesbilitas yng mudah, pertumbuhan jumlah penduduk, peningkatan produk dan atraksi wisata yang baru, adanya investasi dan kerjasama pengelola dan intansi terkait. Sedangkan untuk ancaman yaitu berkembangnya objek wisata lain, kesadaran pengunjung untuk menjaga objek masih kurang, adanya kerusakan lingkungan, kesamaan potensi wisata dengan daerah lain dan gaya hidup masyarakat yang menjadi lebih modern.

\section{Analisis SWOT Strategi Pengembangan Objek Wisata di Kabupaten Batang}

Pembangunan dan pengembangan 5 objek wisata di Kabupaten Batang pada dasarnya adalah untuk menjadikan objek wisata yang ada di Kabupaten Batang menjadi tujuan wisata unggulan sebagai salah satu andalan untuk peningkatan PAD di sektor pariwisata melaluai retribusinya. Dari analisis SWOT Apabila hasil perhitungan tersebut dimasukan ke dalam Matrix Grand Strategy terlihat pengembangan 5 Objek wisata di Kabupaten Batang yaitu Objek wisata Kebun Teh Pagilaran, Objek wisata Bandar Ecopark, objek wisata THR Keramat, objek wisata Pantai Ujungnegoro dan objek wisata Pantai Sigandu berada pada kuadran I, yaitu Objek Wisata berada pada situasi yang menguntungkan karena memiliki kekuatan dan peluang yang lebih besar dari kelemahan dan ancamannya sehingga Objek Wisata di Kabupaten Batang dapat memanfaatkan kekuatan yang dimiliki untuk merebut peluang yang ada atau dengan menggunakan Strategi SO (Strength and Opportunities). Strategi SO (Strength and Opportunities), yaitu strategi yang mengoptimalkan kekuatan (strength) untuk memanfaatkan peluang (Opportunities), adalah: 


\section{Strategi Pengembangan Objek Wisata Kebun}

\section{Teh Pagilaran}

Tabel 3. Analisis Faktor-Faktor Strategi Internal

\begin{tabular}{|c|c|c|c|c|}
\hline No & Faktor Internal & $\begin{array}{l}\text { Rata-rata } \\
\text { Rating }\end{array}$ & $\begin{array}{l}\text { Rata- } \\
\text { rata } \\
\text { Bobot }\end{array}$ & Jumlah \\
\hline \multicolumn{5}{|c|}{ Kekuatan } \\
\hline 1. & Keramahan pengelola objek wisata & 4 & 0.098 & 0.392 \\
\hline 2. & Letak objek wisata yang strategis & 3 & 0.064 & 0.192 \\
\hline 3. & Kondisi keamanan objek wisata yang baik & 4 & 0.106 & 0.424 \\
\hline $4 \cdot$ & $\begin{array}{l}\text { Suasana objek wisata yang memberikan } \\
\text { kenyamanan }\end{array}$ & 4 & 0.098 & 0.392 \\
\hline 5. & Adanya sarana transportasi yang mendukung & 2,5 & 0.083 & 0.207 \\
\hline 6. & Harga tiket yang masih terjangkau & $3 \cdot 5$ & 0.060 & 0.210 \\
\hline \multicolumn{2}{|c|}{ Jumlah Kekuatan } & & & 1.817 \\
\hline & Kelemahan & & & \\
\hline 8. & Promosi objek wisata yang masih kurang & 2 & 0.075 & 0.150 \\
\hline 9. & $\begin{array}{l}\text { Program pengembangan wisata yang masih } \\
\text { sederhana }\end{array}$ & 2 & 0.102 & 0.204 \\
\hline 10. & $\begin{array}{l}\text { Keterbatasan anggaran untuk pengembangan } \\
\text { objek wisata }\end{array}$ & 1,5 & 0.102 & 0.153 \\
\hline 11. & Kebersihan objek wisata yang masih kurang & 3 & 0.068 & 0.204 \\
\hline 12. & $\begin{array}{l}\text { Kurangnya tenaga kerja dalam pengelolaan } \\
\text { objek wisata }\end{array}$ & 2,5 & 0.053 & 0.132 \\
\hline 13. & Minimnya sarana dan prasarana & 1,5 & 0.087 & 0.130 \\
\hline \multicolumn{2}{|c|}{ Jumlah Kelemahan } & & 0.494 & 0.974 \\
\hline
\end{tabular}

Sumber : Data Primer diolah tahun 2016 
Tabel 4. Analisis Faktor-Faktor Strategi Eksternal

\begin{tabular}{llll}
\hline & Rata- & Rata-rata Jumlah \\
& rata & Baktor Eksternal & Rating \\
& & \\
\hline
\end{tabular}

Peluang

1. Otonomi daerah memberi keluasan untuk $\begin{array}{llll}\text { mengembangkan potensi wisata yang ada } & 3 & 0.100 & 0.300\end{array}$

2. Tingkat aksesbilitas yang mudah $0.113 \quad 0.282$

3. Pertumbuhan jumlah penduduk di Kabupaten Batang dan sekitarnya 3

Peningkatan produk dan atraksi wisata

4. dengan memanfaatkan potensi-potensi yang ada

$0.068 \quad 0.204$

$4 \quad 0.109 \quad 0.436$

5. Adanya investasi

$2.5 \quad 0.104 \quad 0.260$

6. Adanya kerjasama antara pengelola objek
6. wisata dan instansi terkait
$3 \quad 0.090$
0.270

Jumlah Peluang

$0.561 \quad 1.752$

Ancaman

$\begin{array}{llllll}\text { 7. Berkembangnya objek wisata lain yang } & & & \\ \text { meningkatkan persaingan } & & & 0.068 & 0.170\end{array}$

$\begin{array}{lllll}\text { 8. Kesadaran wisatawan untuk menjaga objek } & & & \\ 2 & 0.109 & 0.218\end{array}$

9. Adanya Kerusakan lingkunga $\quad 3 \quad 0.100 \quad 0.300$

$\begin{array}{lllll}\text { 10. Adanya kesamaan potensi wisata dengan } & & 0.063 & 0.189\end{array}$

$\begin{array}{llll}\text { 11. Gaya hidup masyarakat yang menjadi lebih } & & & \\ & 2.5 & 0.072 & 0.180\end{array}$

$\begin{array}{lll}\text { Jumlah Ancaman } & 0.434 & 1.057\end{array}$

Sumber : Data Primer diolah tahun 2016 


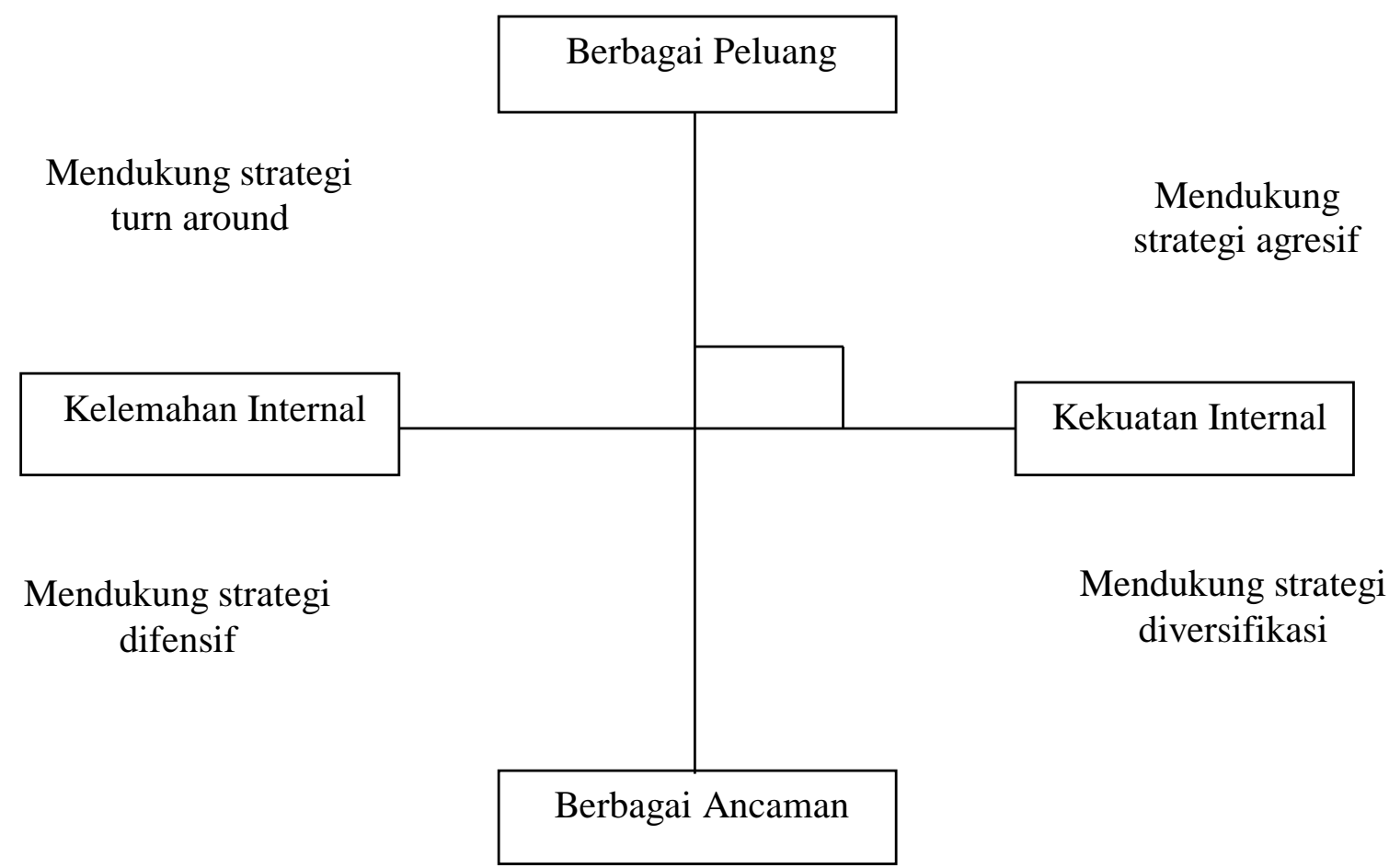

Gambar 1. Matrix Grand Strategy objek wisata Kebun Teh Pagilaran Kebijakan dan Strategi

Keamanan, keramahan pengelola dan masyarakat sekitar Objek Wisata Kebun Teh Pagilaran untuk menjaga keamanan, memberika kesan yang baik terhadap pengunjung sehingga mampu menarik para pengunjung untuk datang ke objek wisata di Kabupaten Batang.

Peningkatan atau penambahan produk dan atraksi permainan wisata yang baru didalam pengembangannya yang mampu memberikan kepuasan bagi para pengunjung sehingga para pengunjung tidak bosan dan ingin berlama-lama di tempat atau objek wisata.

Menjalin kerjasama dengan para investor atau kelompok usah dalam bidang pariwisata untuk ikut dalam mengembangkan objek wisata. Memperbaiki akses transportasi seperti pelebaran jalan dan perbaikan jalan yang rusak untuk menuju ke Objek wisata diperlukan biaya dari pemerintah Daerah atau dari Swasta. Memanfaatkan otonomi daerah untuk mengelola potensi dan daya tarik wisata yang ada di Kolam Renang Bandar (Bandar Ecopark).

Penambahan atraksi wisata seperti penambahan permainan air, permainan ank dengan memanfaatkan pembiayaan atau modal dari pemerinta Daerah.

Dengan adanya permainan, sarana fasilitas di objek wisata yang banyak akan menarik para pengunjung dengan memanfatkan pertumbuhan jumlah penduduk di Kabupaten Batang Memperbanyak tempat istirahat, penjualan souvenir dan tempat makan untuk menunjang kenyamanan bagi para pengunjung 


\section{Strategi Pengembangan Objek Wisata Bandar Ecopark}

Tabel 5 .Analisis Faktor-Faktor Strategi Internal

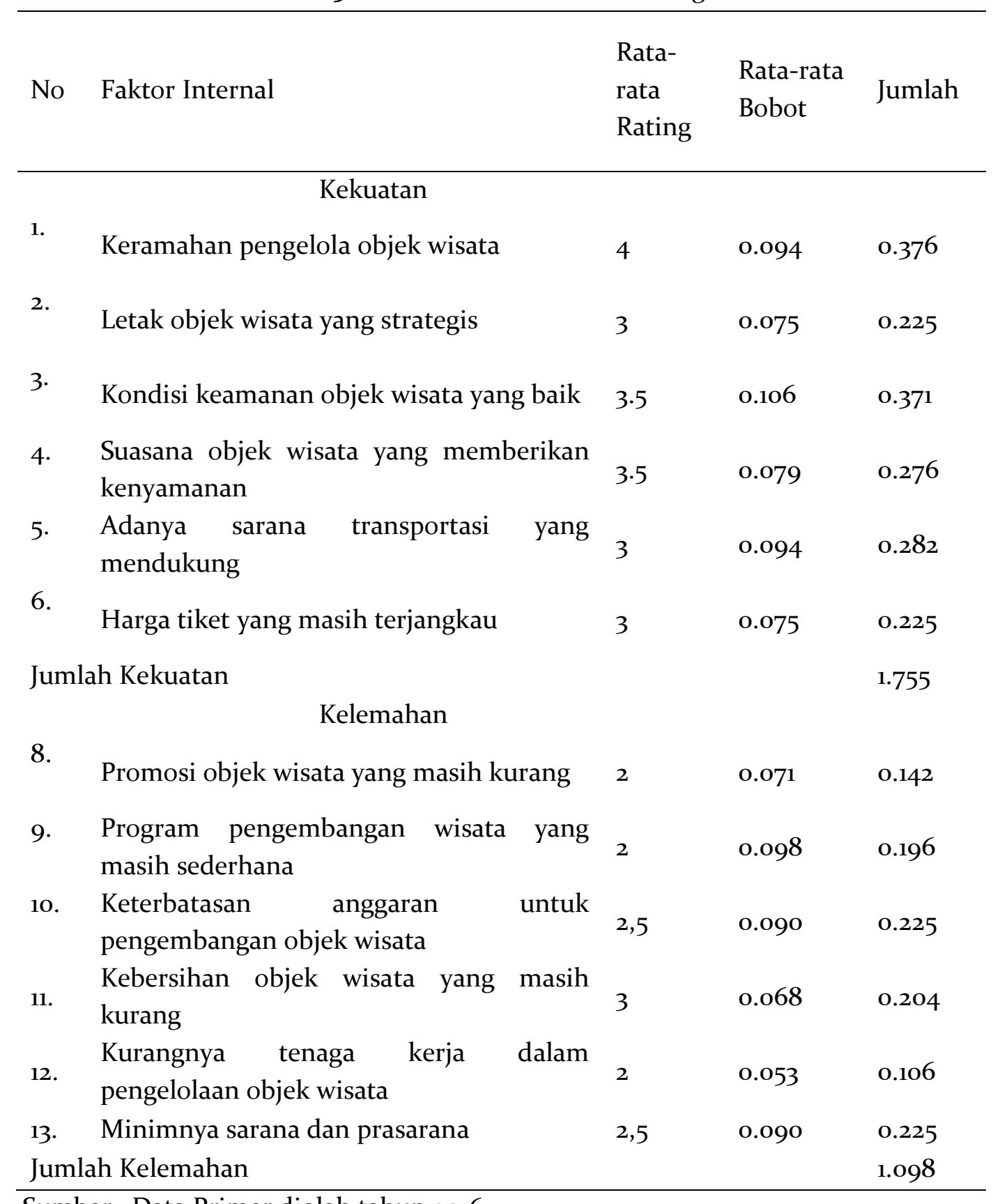

Sumber : Data Primer diolah tahun 2016 


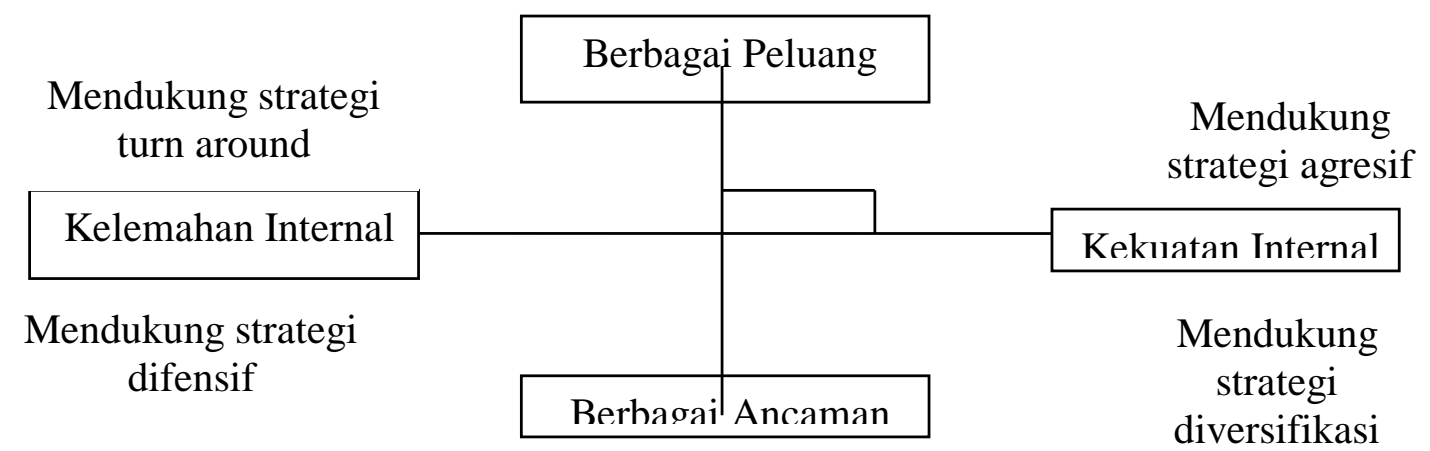

Gambar 2. Matrix Grand Strategy objek wisata Bandar Ecopark

Kebijakan dan Strategi

\section{Strategi Pengembangan Objek Wisata Pantai Sigandu}

Tabel 6. Analisis Faktor-Faktor Strategi Internal

$\begin{array}{llll}\text { No Faktor Internal } & \text { Rata-rata } & \text { Rata-rata Bobot Jumlah } \\ & \text { Rating } & \text { Jutal }\end{array}$

\begin{tabular}{|c|c|c|c|c|}
\hline \multicolumn{5}{|c|}{ Kekuatan } \\
\hline 1. & Keramahan pengelola objek wisata & 3 & 0.090 & 0.270 \\
\hline 2. & Letak objek wisata yang strategis & $3 \cdot 5$ & 0.071 & 0.248 \\
\hline 3. & Kondisi keamanan objek wisata yang baik & $3 \cdot 5$ & 0.098 & 0.343 \\
\hline 4. & $\begin{array}{l}\text { Suasana objek wisata yang memberikan } \\
\text { kenyamanan }\end{array}$ & 3 & 0.071 & 0.213 \\
\hline 5. & Adanya sarana transportasi yang mendukung & 3 & 0.083 & 0.249 \\
\hline 6. & Harga tiket yang masih terjangkau & $3 \cdot 5$ & 0.083 & 0.290 \\
\hline \multicolumn{4}{|c|}{ Jumlah Kekuatan } & 1.614 \\
\hline \multicolumn{5}{|c|}{ Kelemahan } \\
\hline 8. & Promosi objek wisata yang masih kurang & 2.5 & 0.087 & 0.217 \\
\hline 9. & $\begin{array}{l}\text { Program pengembangan wisata yang masih } \\
\text { sederhana }\end{array}$ & 2 & 0.087 & 0.174 \\
\hline 10. & $\begin{array}{l}\text { Keterbatasan anggaran untuk pengembangan objek } \\
\text { wisata }\end{array}$ & 1,5 & 0.106 & 0.159 \\
\hline 11. & Kebersihan objek wisata yang masih kurang & 2 & 0.064 & 0.128 \\
\hline 12. & $\begin{array}{l}\text { Kurangnya tenaga kerja dalam pengelolaan objek } \\
\text { wisata }\end{array}$ & 2,5 & 0.053 & 0.132 \\
\hline 13. & Minimnya sarana dan prasarana & 1,5 & 0.102 & 0.153 \\
\hline \multicolumn{3}{|c|}{ Jumlah Kelemahan } & 0.494 & 0.964 \\
\hline
\end{tabular}

Sumber : Data Primer diolah tahun 2016 


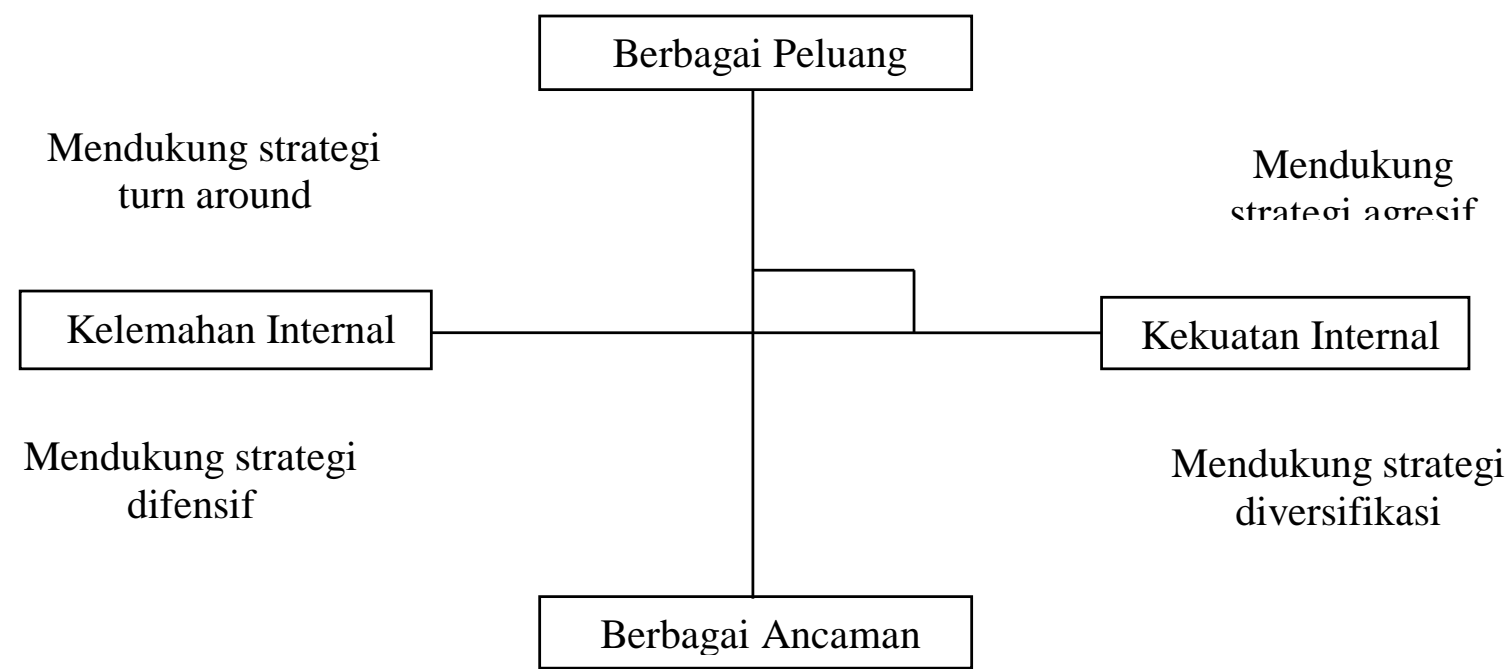

Gambar 3. Matrix Grand Strategy objek wisata Pantai Sigandu

Kebijakan dan Strategi

Memanfaatkan otonomi daerah untuk pengunjung ke objek wisata panta Sigandu.Letak mengelola potensi alam dan objek wisata yang objek wisata yang strategis dapat dijangkau oleh menarik. Adanya investasi swasta seperti para wisatawan baik dari dalam wilayah Batang pembanguanan Dolphint center akan menambah maupun luar Daerah sehingga dapat menambah wahana atau tujuan untuk wisatawan. Adanya kunjungan wisatawan. Sarana transportasi dan transportasi yang mendukung dan aksesbilitas yang mudah akan mempermudah para akses yang mudah dapat dimanfaatkan untuk pengadaan penggunaan delman atau andong.

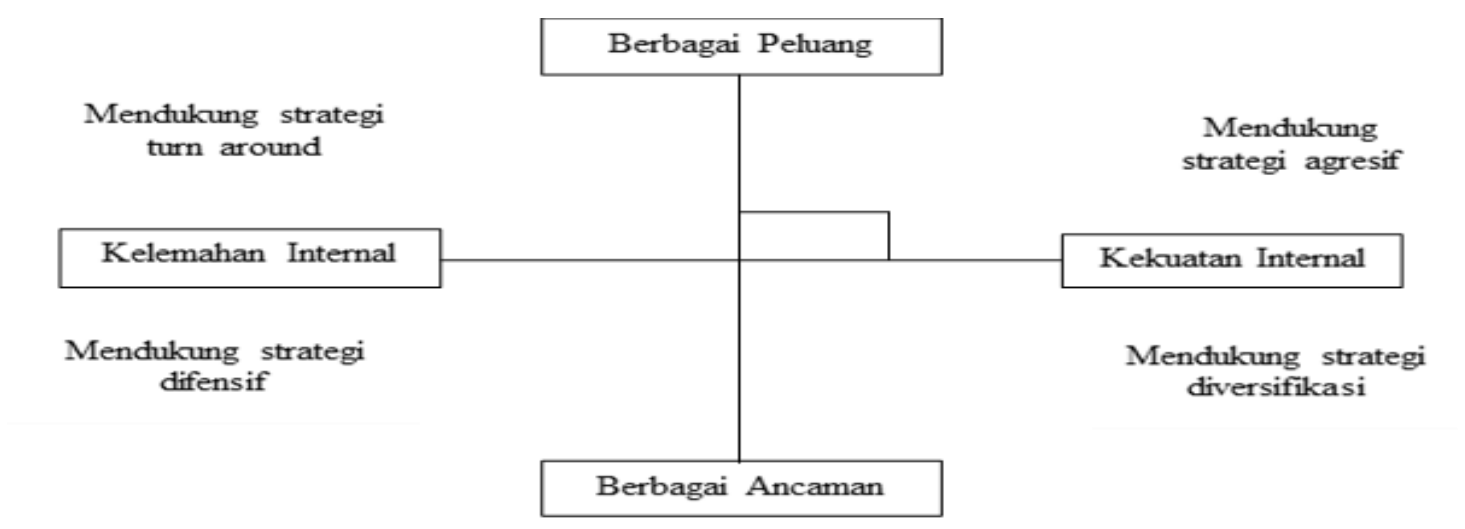

Gambar 4. Matrix Grand Strategy objek wisata Taman Hiburan Rakyat

Kebijakan dan Strategi

Sumber : Data Primer diolah tahun 2016 
Strategi Pengembangan Objek Wisata THR Keramat

Memanfaatkan letak objek wisata yang strategis dan memberi kenyamanan untuk dikembangkan lebih baik lagi.Meningkatkan Keamanan, keramahan pengelola dan masyarakat sekitar objek wisata guna menjaga kenyamanan dan menarik pengunjung di Kabupaten Batang dan sekitarnya.

Menambah sarana, fasilitas serta atraksi wisata yang baru dengan bekerja sama melalui Dinas Pariwisata. Memperbaiki akses transportasi seperti jalan untuk menuju ke Objek wisata seperti perlebaran jalan agar angkutan umum seperti bus bisa masuk ke objek wisata

\section{Strategi Pengembangan Objek Wisata Pantai Ujungnegoro}

Tabel 7. Analisis Faktor-Faktor Strategi Internal

No Faktor Internal

Kekuatan

1. Keramahan pengelola objek wisata

2. Letak objek wisata yang strategis

3. baik

4. Suasana objek wisata yang memberikan

4. kenyamanan

Adanya sarana transportasi yang

5. mendukung

6. Harga tiket yang masih terjangkau

Jumlah Kekuatan

\section{Kelemahan}

8. Promosi objek wisata yang masih kurang

9. Program pengembangan wisata yang

9. masih sederhana

10. Keterbatasan anggaran untuk

10. pengembangan objek wisata

11. Kebersihan objek wisata yang masih

11. kurang

Kurangnya tenaga kerja dalam

12. pengelolaan objek wisata

13. Minimnya sarana dan prasarana

Jumlah Kelemahan

Sumber : Data Primer diolah tahun 2016 $\begin{array}{lll}\text { Rata-rata } & \text { Rata-rata } \\ \text { Rating } & \text { Bobot }\end{array}$ Jumlah
0.083

0.290

4

0.071

0.284

3

0.098

0.294

3

0.071

0.213

$3 \cdot 5$

0.087

0.304

$3 \cdot 5$

0.075

0.262

1.648

$\begin{array}{lll}2.5 & 0.087 & 0.217 \\ 2 & 0.090 & 0.180\end{array}$

1,5

0.102

0.153

2

0.071

0.142

1.5

$0.056 \quad 0.084$

2

$0.102 \quad 0.204$

0.494

0.980 


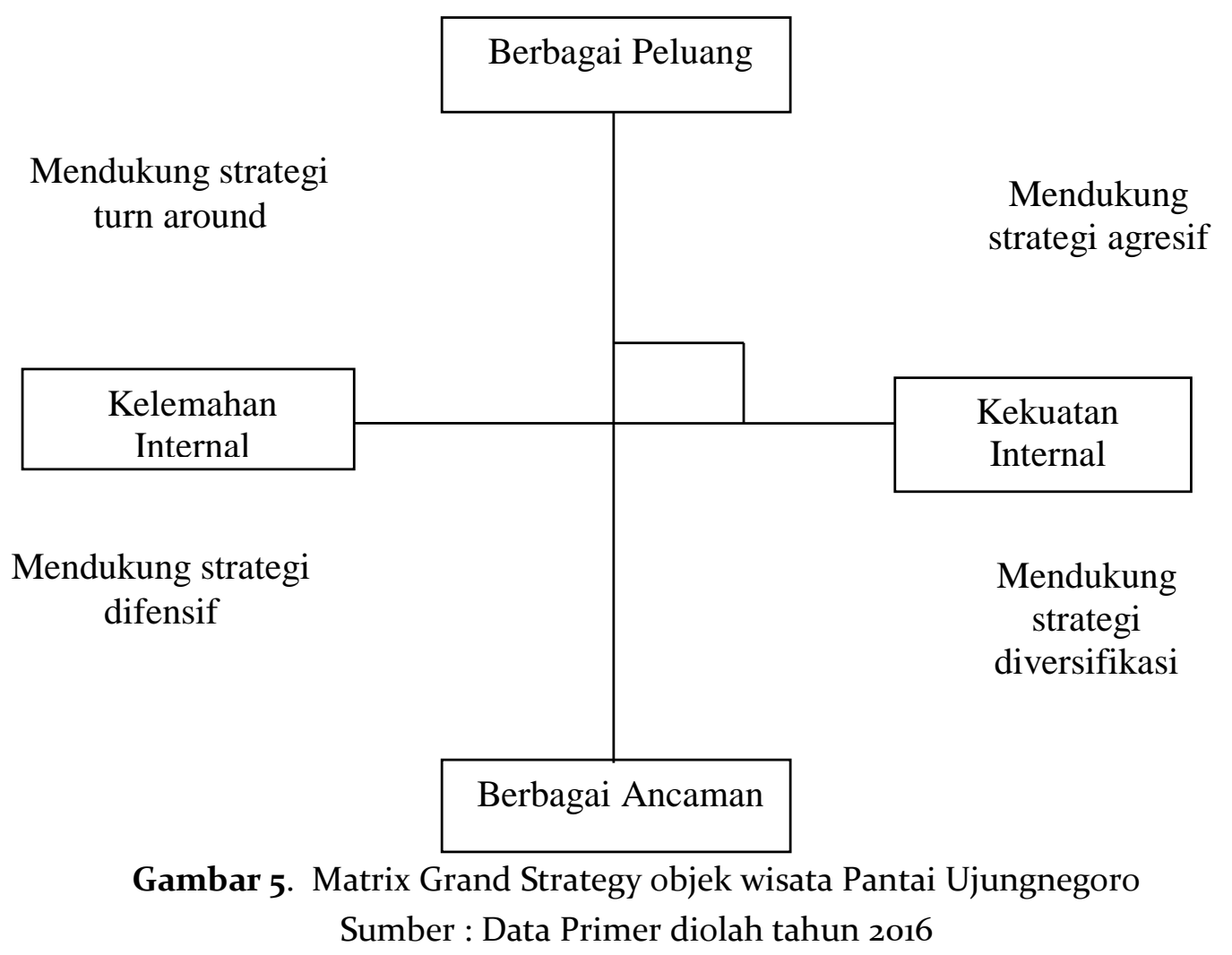

\section{Kebijakan dan Strategi}

Memanfaatkan otonomi daerah untuk mengelola potensi alam dan objek wisata yang menarik. Adanya peninggalan Makam dapat digunakan sebagai daya tarik lain di objek wisata perlu dimanfaatkan sebagai wisata religi. Adanya transportasi yang mendukung dan aksesbilitas yang mudah akan mempermudah para pengunjung ke objek wisata panta Sigandu.

Letak objek wisata yang strategis dapat dijangkau oleh para wisatawan baik dari dalam wilayah Batang maupun luar Daerah sehingga dapat menambah kunjungan wisatawan. Sarana transportasi dan akses yang mudah dapat dimanfaatkan untuk pengadaan penggunaan delman atau andong. Kontribusi Objek Wisata terhadap Penerimaan Retribusi di Kabupaten Batang, dengan meningkatnya jumlah pendapatan Objek Wisata, maka secara tidak langsung akan ikut menambah jumlah PAD Kabupaten Batang melalui retribusinya. Dinas Kebudayaan dan Pariwisata sebagai pengelola objek wisata yang berusaha melayani masyarakat melalui sarana rekreasi telah memperoleh pendapatan atas penyelenggaraan jasa pariwisata yang telah diberikan. Dengan demikian, yang dimaksud pendapatan objek wisata di Kabupaten Batang adalah jumlah pendapatan yang diperoleh dari hasil penjualan karcis kepada para pengunjung objek wisata. Untuk dapat gambaran yang lebih jelas mengenai pendapatan objek wisata di Kabupaten Batang dapat dilihat pada tabel berikut : 
Tabel 8. Pendapatan Objek Wisata Yang Diperoleh Dari Tiket Masuk

Tahun 2008- 2014

PENDAPATAN PERTAHUN

(Ribuan Rupiah)

\begin{tabular}{cc}
\hline Tahun & Pendapatan Objek Wisata \\
\hline 2008 & 282.569 .400 \\
2009 & 377.686 .500 \\
2010 & 666.966 .700 \\
2011 & 628.051 .400 \\
2012 & 827.735 .200 \\
2013 & 786.238 .500 \\
2014 & 769.495 .500 \\
\hline
\end{tabular}

Sumber: DPPKAD Kabupaten Batang 2016

Berdasarkan tabel 12 dapat diketahui bahwa perkembangan pendapatan dari Objek Wisata di Kabupaten Batang dari tahun 2008-2014 tertinggi terjadi pada tahun 2012 yaitu sebesar 827.735.200. akan tetapi pada tahun 2013 sampai tahun 2014 pendapatan objek wisata di Kabupaten Batang mengalami penurunan dari semula RP.827.735.200 menjadi RP.786.238.500 pada tahun 2013 dan mengalami penurunan lagi pada tahun 2014 menjadi Rp.769.495.5oo. Untuk retribusi pendapatan diperoleh melalui tiket masuk seharga Rp 3.00o-Rp.5.00o per orang. Kenaikan dan penurunan pendapatan disebabkan oleh beberapa faktor yaitu jumlah wisatawan serta besarnya tarif masuk wisatwan. Bila jumlah wisatawan meningkat, maka pendapatan juga cenderung meningkat. Berdasarkan tabel 13 dapat dilihat pemasukan pendapatan objek wisata di

Kabupaten Batang terhadap Retribusi dan PAD Kabupaten Batang per tahunnya memiliki kontribusi yang masih kecil. Kontribusi terbesar objek wisata di Kabupaten Batang terhadap Retribusi dan PAD Kabupaten Batang ada pada tahun 2012 untuk kontribusi terhadap retribusi yaitu sebesar $5,07 \%$ dan pada tahun 2010 untuk kontribusi terhadap PAD yaitu sebesar 1,46\%. Dan kontribusi terendah objek wisata di Kabupaten Batang untuk kontribusi terhadap retribusi ada pada tahun 2008 yaitu sebesar 1,35. Dan kontribusi terhadap PAD paling rendah tahun 2014 yaitu sebesar 0,44\%. 
Tabel 9. Jumlah Pendapatan Retribusi Objek Wisata,Retribusi Daerah dan Pendapatan Asli Daerah (PAD) Kabupaten Batang Tahun 2008-2014

\begin{tabular}{cccccc}
\hline \multicolumn{2}{l}{$\begin{array}{l}\text { PENDAPATAN PERTAHUN } \\
\text { (Ribuan Rupiah) }\end{array}$} & \multicolumn{5}{l}{} \\
\hline Tahun & $\begin{array}{c}\text { Pendapatan } \\
\text { Objek Wisata }\end{array}$ & Retribusi Daerah & $\begin{array}{c}\text { Kontribusi } \\
(\%)\end{array}$ & $\begin{array}{c}\text { Pendapatan Asli } \\
\text { Daerah }\end{array}$ & $\begin{array}{c}\text { Kontribusi } \\
(\%)\end{array}$ \\
\hline 2008 & 282.569 .400 & 20.811 .791 .556 & 1,35 & 41.192 .714 .868 & 0,68 \\
2009 & 377.686 .500 & 22.764 .685 .984 & 1,65 & $44.643 .602 .159,48$ & 0,84 \\
2010 & 666.966 .700 & 24.687 .956 .366 & 2,70 & 45.421 .689 .588 & 1,46 \\
2011 & 628.051 .400 & 29.644 .279 .421 & 2,11 & 60.155 .029 .031 & 1,04 \\
2012 & 827.735 .200 & 16.303 .639 .041 & 5,07 & 84.720 .049 .515 & 0,97 \\
2013 & 786.238 .500 & 35.812 .498 .970 & 2,19 & 112.339 .381 .119 & 0,69 \\
2014 & 769.495 .500 & 25.247 .348 .616 & 3,04 & $172.638 .212 .951,92$ & 0,44 \\
\hline
\end{tabular}

Sumber : DPPKAD Kabupaten Batang 2016

\section{SIMPULAN}

Berdasarkan hasil analisis SWOT, dapat diketahui bahwa strategi pengembangan Objek Wisata di Kabupaten Batang berada pada kuadran I. Pada kuadran ini Objek Wisata di Kabupaten Batang berada pada situasi yang menguntungkan,karena objek wisata di Kabupaten Batang dapat menggunakan kekuatan yang dimiliki untuk memanfaatkan peluang yang ada. Kontribusi terbesar pendapatan objek wisata terhadap retribusi daerah ada pada tahun 2012 sebesar 5,07\% dan terhadap PAD Kabupaten Batang ada pada tahun 2010 yaitu sebesar 1,46\%. Dan kontribusi terendah objek wisata di Kabupaten Batang untuk kontribusinya terhadap retribusi Daerah ada pada tahun 2008 yaitu sebesar 1,35. Dan kontribusi terhadap PAD paling rendah tahun 2014 yaitu sebesar o,44\%.

\section{DAFTAR PUSTAKA}

Arikunto, Suharsimi. 2006. Prosedur Penelitian Suatu Pendekatan Praktik. Jakarta : Rineka Cipta

BPS Kabupaten Batang. 2008-2014. Batang Dalam Angka. Batang.

Damanik,J dan Weber,H.F. (2006) Perencanaan Ekowisata: Dari Teori ke Aplikasi. Penerbit Andi. Yogyakarta.
Dinas Pendapatan Pengelolaan Keuangan dan Aset Daerah Kabupaten Batang. 2008, 2009, 2010, 2011, 2012, 2013, 2014.

Fandeli C.1995, Dasar-Dasar Manajemen Kepariwisataan Alam, Penerbit Liberty, Yogyakarta.

Fandeli, Chafid. 1999. Dasar-dasar Manajemen Kepariwisataan Alam. Yogyakarta:Liberty.

Halim, Abdul (2004), Akuntansi Keuangan Daerah, Jakarta : Salemba Empat.

Mardiasmo, 2002. Membangun Manajemen Keuangan Daerah. Yogyakarta.

Nyoman S Pendit. 2002. Ilmu Pariwisata Sebuah Pengantar Perdana. Jakarta:

Pradikta, Angga. 2013. Strategi Pengembangan Objek Wisata Waduk Gunungrowo Indah dalam Upaya meningkatkan Pendapatan Asli Daerah (PAD) Kabupaten Pati. EDAJ: Economics Development Analysis Journal 2 (4). (Diunduh pada 3 Januari 2017)

Rangkuti, Freddy. 2006. Analisis SWOT : Teknik Membedah Kasus Bisnis. Jakarta: PT Gramedia Pustaka Utama.

Sammeng, Andi Mappi. 2001. Cakrawala Pariwisata. Jakarta : Balai Pustaka

Undang-Undang Nomor 34,200o Tentang Perubahan Undang-Undang Nomor 18 Tahun 1997 Tentang Pajak Daerah dan Retribusi Daerah.

Undang-undang Nomor 32 Tahun 2004 tentang Pemerintahan Daerah. 2004.

Undang-Undang RI Nomor 34 Tahun 20oo. Tentang Pajak Daerah dan Retribusi Daerah.Jakarta. 


\section{APPENDIX}

Tabel 1o. Analisis Faktor-Faktor Strategi Eksternal

\begin{tabular}{|c|c|c|c|c|}
\hline No & Faktor Eksternal & $\begin{array}{l}\text { Rata-rata } \\
\text { Rating }\end{array}$ & $\begin{array}{l}\text { Rata-rata } \\
\text { Bobot }\end{array}$ & Jumlah \\
\hline \multicolumn{5}{|c|}{ Peluang } \\
\hline 1. & $\begin{array}{l}\text { Otonomi daerah memberi keluasan untuk } \\
\text { mengembangkan potensi wisata yang ada }\end{array}$ & 3 & 0.077 & 0.231 \\
\hline 2. & Tingkat aksesbilitas yang mudah & $3 \cdot 5$ & 0.104 & 0.364 \\
\hline 3 & $\begin{array}{l}\text { Pertumbuhan jumlah penduduk di Kabupaten } \\
\text { Batang dan sekitarnya }\end{array}$ & 3 & 0.090 & 0.270 \\
\hline 4 . & $\begin{array}{l}\text { Peningkatan produk dan atraksi wisata dengan } \\
\text { memanfaatkan potensi-potensi yang ada }\end{array}$ & 3 & 0.109 & 0.327 \\
\hline 5 . & Adanya investasi & 3 & 0.077 & 0.231 \\
\hline 6. & $\begin{array}{l}\text { Adanya kerjasama antara pengelola objek wisata } \\
\text { dan instansi terkait }\end{array}$ & $3 \cdot 5$ & 0.109 & 0.381 \\
\hline \multicolumn{2}{|c|}{ Jumlah Peluang } & & 0.561 & 1.804 \\
\hline \multicolumn{5}{|c|}{ Ancaman } \\
\hline 7. & $\begin{array}{l}\text { Berkembangnya objek wisata lain yang } \\
\text { meningkatkan persaingan }\end{array}$ & 1.5 & 0.072 & 0.108 \\
\hline 8. & $\begin{array}{l}\text { Kesadaran wisatawan untuk menjaga objek wisata } \\
\text { masih rendah }\end{array}$ & 2 & 0.118 & 0.236 \\
\hline 9 . & Adanya Kerusakan lingkunga & 1.5 & 0.095 & 0.142 \\
\hline 10. & $\begin{array}{l}\text { Adanya kesamaan potensi wisata dengan daerah } \\
\text { lain }\end{array}$ & 2 & 0.068 & 0.136 \\
\hline 11. & Gaya hidup masyarakat yang menjadi lebih modern & 2.5 & 0.077 & 0.192 \\
\hline \multicolumn{2}{|c|}{ Jumlah Ancaman } & & 0.434 & 0.815 \\
\hline
\end{tabular}

Sumber : Data Primer diolah tahun 2016 
Tabel 11. Analisis Faktor-Faktor Strategi Internal

\begin{tabular}{|c|c|c|c|c|}
\hline No & Faktor Internal & $\begin{array}{l}\text { Rata-rata } \\
\text { Rating }\end{array}$ & $\begin{array}{l}\text { Rata-rata } \\
\text { Bobot }\end{array}$ & Jumlah \\
\hline \multicolumn{5}{|c|}{ Kekuatan } \\
\hline 1. & Keramahan pengelola objek wisata & 2.5 & 0.079 & 0.197 \\
\hline 2. & Letak objek wisata yang strategi & $3 \cdot 5$ & 0.064 & 0.224 \\
\hline 3. & Kondisi keamanan objek wisata yang baik & 3 & 0.098 & 0.294 \\
\hline $4 \cdot$ & $\begin{array}{l}\text { Suasana objek wisata yang memberikan } \\
\text { kenyamanan }\end{array}$ & $3 \cdot 5$ & 0.083 & 0.290 \\
\hline 5. & $\begin{array}{l}\text { Adanya sarana transportasi yang } \\
\text { mendukung }\end{array}$ & 3 & 0.087 & 0.261 \\
\hline 6. & Harga tiket yang masih terjangkau & $3 \cdot 5$ & 0.071 & 0.248 \\
\hline \multicolumn{2}{|c|}{ Jumlah Kekuatan } & & & 1.515 \\
\hline \multicolumn{5}{|c|}{ Kelemahan } \\
\hline 8. & Promosi objek wisata yang masih kurang & 2 & 0.075 & 0.150 \\
\hline 9. & $\begin{array}{l}\text { Program pengembangan wisata yang } \\
\text { masih sederhana }\end{array}$ & 2.5 & 0.109 & 0.272 \\
\hline 10. & $\begin{array}{l}\text { Keterbatasan anggaran } \quad \text { untuk } \\
\text { pengembangan objek wisata }\end{array}$ & 2 & 0.098 & 0.196 \\
\hline 11. & $\begin{array}{l}\text { Kebersihan objek wisata yang masih } \\
\text { kurang }\end{array}$ & 2.5 & 0.060 & 0.150 \\
\hline 12. & $\begin{array}{l}\text { Kurangnya tenaga kerja dalam } \\
\text { pengelolaan objek wisata }\end{array}$ & 1.5 & 0.068 & 0.102 \\
\hline 13. & Minimnya sarana dan prasarana & 1,5 & 0.068 & 0.153 \\
\hline Jun & Kelemahan & & 0.494 & 1.023 \\
\hline
\end{tabular}

Sumber : Data Primer diolah tahun 2016 
Tabel 12. Analisis Faktor-Faktor Strategi Eksternal

\begin{tabular}{lllll}
\hline & & Rata-rata & Rata-rata \\
Roting & Bobot & Jumlah
\end{tabular}

Peluang

1. Otonomi daerah memberi keluasan untuk mengembangkan potensi wisata yang ada

3

0.081

0.243

Tingkat aksesbilitas yang mudah

2.

Tingkat aksesbilitas yang mudah

3

Pertumbuhan jumlah penduduk di

3. Kabupaten Batang dan sekitarnya

3

$0.113 \quad 0.339$

Peningkatan produk dan atraksi wisata

4. dengan memanfaatkan potensi-potensi

$\begin{array}{lll}0.081 & 0.243\end{array}$

$\begin{array}{lll}0.095 & 0.285\end{array}$

5. Adanya investasi

3

0.077

0.231

6. Adanya kerjasama antara pengelola objek wisata dan instansi terkait

$3 \cdot 5$

0.109

0.381

Jumlah Peluang

$0.561 \quad 1.722$

Ancaman

7. Berkembangnya objek wisata lain yang
meningkatkan persaingan

$1.5 \quad 0.077 \quad 0.115$

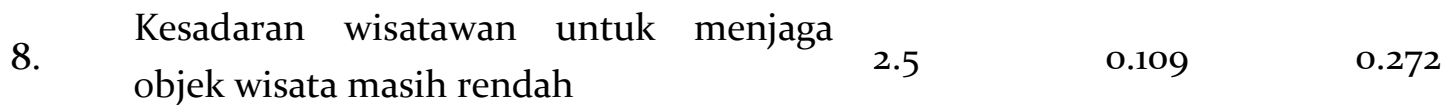

$\begin{array}{lllll}\text { 9. } & \text { Adanya Kerusakan lingkunga } & 3 & 0.104 & 0.312\end{array}$

\begin{tabular}{llcc} 
10. $\begin{array}{l}\text { Adanya kesamaan potensi wisata dengan } \\
\text { daerah lain }\end{array}$ & 1.5 & 0.081 & 0.121 \\
$\begin{array}{l}\text { Gaya hidup masyarakat yang menjadi lebih } \\
\text { modern }\end{array}$ & 2.5 & 0.068 & 0.170 \\
\hline Jumlah Ancaman & & 0.434 & 0.991
\end{tabular}

Sumber : Data Primer diolah tahun 2016 
Tabel 13. Analisis Faktor-Faktor Strategi Eksternal

\begin{tabular}{|c|c|c|c|c|}
\hline No & Faktor Eksternal & $\begin{array}{l}\text { Rata-rata } \\
\text { Rating }\end{array}$ & $\begin{array}{l}\text { Rata-rata } \\
\text { Bobot }\end{array}$ & Jumlah \\
\hline \multicolumn{5}{|c|}{ Peluang } \\
\hline 1. & $\begin{array}{l}\text { Otonomi daerah memberi keluasan } \\
\text { untuk mengembangkan potensi wisata } \\
\text { yang ada }\end{array}$ & 3 & 0.072 & 0.216 \\
\hline 2. & Tingkat aksesbilitas yang mudah & $3 \cdot 5$ & 0.100 & 0.350 \\
\hline 3. & $\begin{array}{l}\text { Pertumbuhan jumlah penduduk di } \\
\text { Kabupaten Batang dan sekitarnya }\end{array}$ & 3 & 0.095 & 0.285 \\
\hline 4. & $\begin{array}{l}\text { Peningkatan produk dan atraksi wisata } \\
\text { dengan memanfaatkan potensi-potensi } \\
\text { yang ada }\end{array}$ & 3 & 0.100 & 0.300 \\
\hline 5 & Adanya investasi & 2.5 & 0.081 & 0.202 \\
\hline 6. & $\begin{array}{l}\text { Adanya kerjasama antara pengelola } \\
\text { objek wisata dan instansi terkait }\end{array}$ & $3 \cdot 5$ & 0.104 & 0.364 \\
\hline \multicolumn{2}{|c|}{ Jumlah Peluang } & & 0.561 & 1.717 \\
\hline \multicolumn{5}{|c|}{ Ancaman } \\
\hline 7. & $\begin{array}{l}\text { Berkembangnya objek wisata lain yang } \\
\text { meningkatkan persaingan }\end{array}$ & 2 & 0.081 & 0.162 \\
\hline 8. & $\begin{array}{l}\text { Kesadaran wisatawan untuk menjaga } \\
\text { objek wisata masih rendah }\end{array}$ & 2 & 0.104 & 0.208 \\
\hline 9. & Adanya Kerusakan lingkunga & 1.5 & 0.104 & 0.156 \\
\hline 10. & $\begin{array}{l}\text { Adanya kesamaan potensi wisata dengan } \\
\text { daerah lain }\end{array}$ & 1.5 & 0.072 & 0.108 \\
\hline 11. & $\begin{array}{l}\text { Gaya hidup masyarakat yang menjadi } \\
\text { lebih modern }\end{array}$ & 2.5 & 0.081 & 0.202 \\
\hline \multicolumn{2}{|c|}{ Jumlah Ancaman } & & 0.434 & 0.836 \\
\hline
\end{tabular}

Sumber : Data Primer diolah tahun 2016 